
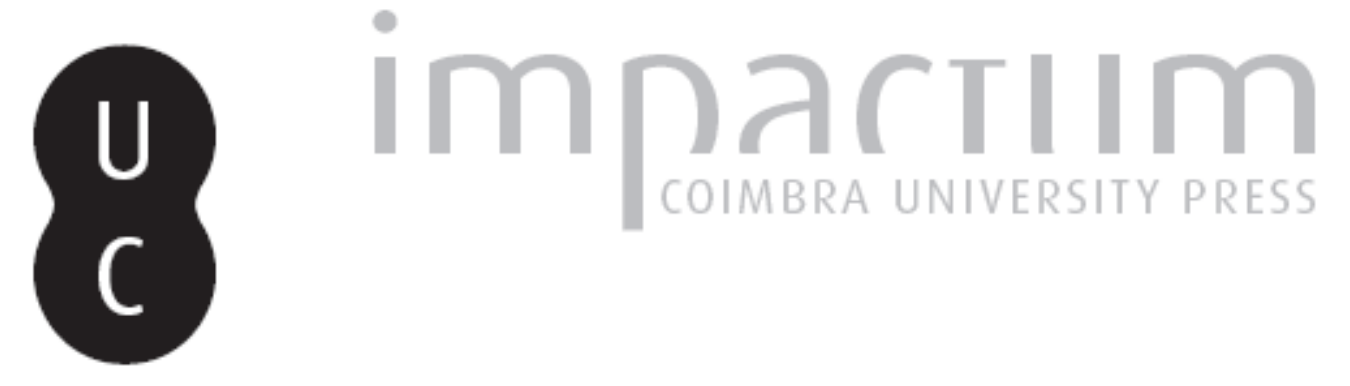

Como destruir uma biblioteca sem ser apanhado e outras coisas interessantes

Autor(es): $\quad$ Loureiro, João Diogo Publicado por: Associação Portuguesa de Estudos Clássicos; Instituto de Estudos

URL persistente:

URI:http://hdl.handle.net/10316.2/30403

DOI:

DOI:http://dx.doi.org/10.14195/0872-2110_53_16

Accessed : $\quad$ 26-Apr-2023 14:06:51

A navegação consulta e descarregamento dos títulos inseridos nas Bibliotecas Digitais UC Digitalis, UC Pombalina e UC Impactum, pressupõem a aceitação plena e sem reservas dos Termos e Condições de Uso destas Bibliotecas Digitais, disponíveis em https://digitalis.uc.pt/pt-pt/termos.

Conforme exposto nos referidos Termos e Condições de Uso, o descarregamento de títulos de acesso restrito requer uma licença válida de autorização devendo o utilizador aceder ao(s) documento(s) a partir de um endereço de IP da instituição detentora da supramencionada licença.

Ao utilizador é apenas permitido o descarregamento para uso pessoal, pelo que o emprego do(s) título(s) descarregado(s) para outro fim, designadamente comercial, carece de autorização do respetivo autor ou editor da obra.

Na medida em que todas as obras da UC Digitalis se encontram protegidas pelo Código do Direito de Autor e Direitos Conexos e demais legislação aplicável, toda a cópia, parcial ou total, deste documento, nos casos em que é legalmente admitida, deverá conter ou fazer-se acompanhar por este aviso.

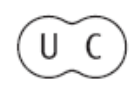




\section{Boletim de \\ Estudos Clássicos}

Associação Portuguesa de Estudos Clássicos Instituto de Estudos Clássicos

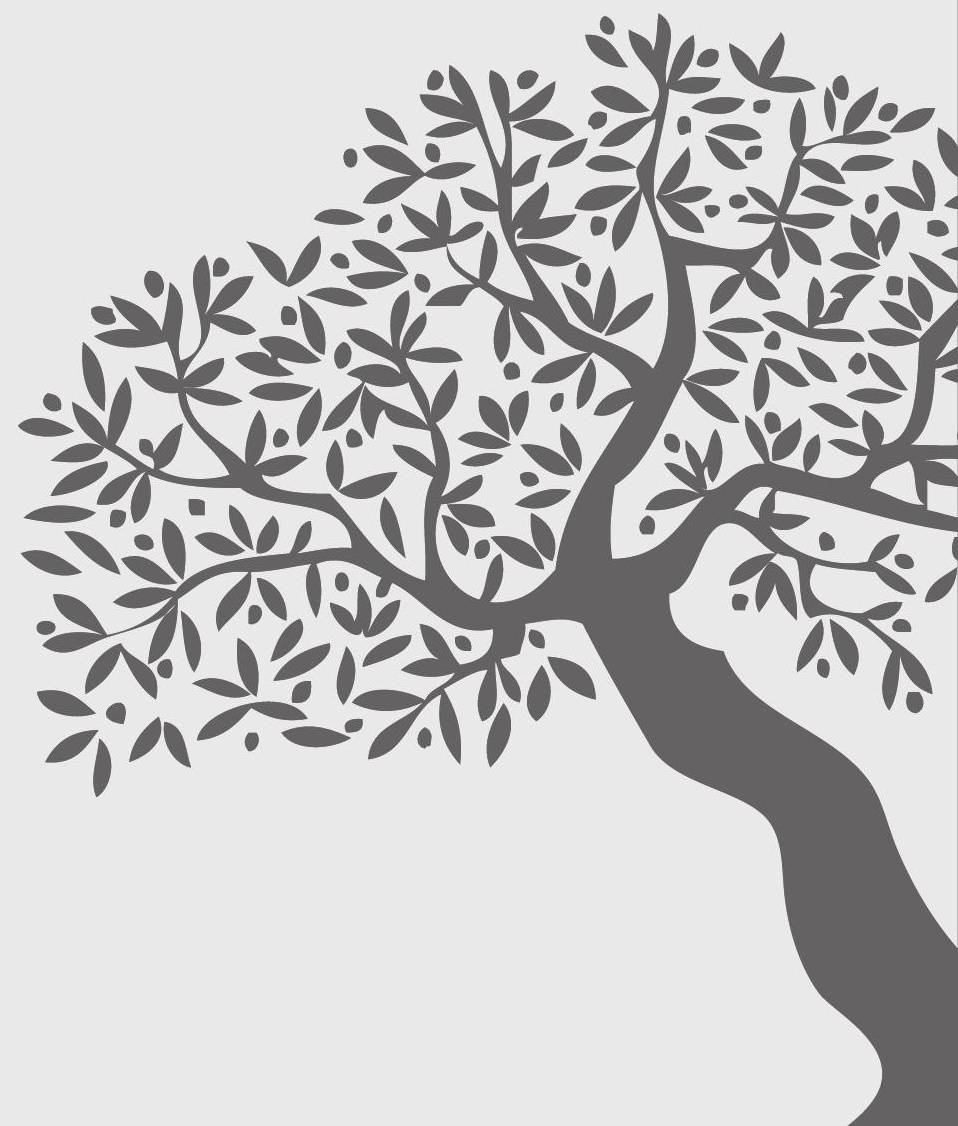

Coimbra

Junho de 2010 


\title{
COMO DESTRUIR UMA BIBLIOTECA SEM SER APANHADO E OUTRAS COISAS INTERESSANTES
}

\author{
A PROPÓSITO DE ÁGORA (2009), DE AMENÁBAR - I
}

Ai! disse eu enquanto andávamos a ver tudo isso, tem sido sem dúvida um jogo sumptuoso do destino abater os templos e dar às crianças as suas pedras, destroços para elas arremassarem, e fazer dos deuses mutilados bancos diante das cabanas dos camponeses... Hölderlin, Hipérion ou O Eremita da Grécia, Carta 30

(trad.: Maria Teresa Dias Furtado)

Estreou em Dezembro nas salas portuguesas Ágora, o mais recente filme de Amenábar, centrado na figura de Hipácia, a filósofa neoplatónica alexandrina que foi brutalmente assassinada por um grupo de cristãos em 415 . Não nos propomos aqui avaliar o filme do ponto de vista cinematográfico, pois que este não é o espaço próprio para isso, mas tão somente, como classicistas, verificar a sua fidelidade aos eventos históricos em que se inspira. Ágora aborda um período que é francamente mal conhecido até de muitos dos estudiosos da área de Clássicas, especialmente difícil e complexo, e, portanto, para podermos analisar com alguma correcção e justiça o filme, optámos por dividir o nosso comentário. Propomo-nos tratar neste número da revista apenas a primeira parte/metade do filme, que culmina com a depredação do Serapeum, em 391, por uma turba cristã. Três questões orientam a nossa investigação: (1) Havia livros no Serapeum? (2) O Serapeum foi destruído? (3) A Biblioteca foi destruída?

Procuremos a resposta às nossas perguntas.

O Serapeum, complexo de edifícios na acrópole alexandrina (ver figura 1), fundamentalmente uma construção de Ptolomeu III ${ }^{1}$, e dedicado a Serápis,

1 Os dados arqueológicos são bastante explícitos quanto a isso (McKenzie et al., 2004: 81-82). 
divindade ctónica promovida ao estatuto de deus tutelar da cidade e em cujo novo culto se fundem, com vista a promover a reunião dos dois povos, elementos gregos e egípcios, parece, de facto, ter tido uma colecção de livros. O Serapeum não deve, porém, ser confundido com a bem mais conhecida Biblioteca de Alexandria, fundada por Ptolomeu I como complemento do Museu, o santuário das Musas, perto do Palácio Real, a maior do mundo de então, com meio milhão ou mais de rolos já no tempo de Ptolomeu II (Brill's New Pauly, s.v. Library, II.B.2). O filme faz o erro, talvez não inocente, de as identificar.

A Biblioteca do Museu, porém, já não existia em 391. Na esteira de Plutarco (Caes. 49), alguma historiografia subscreveu a tese de que a destruição desta se teria ficado a dever ao fogo que consumiu o porto da cidade durante a guerra pela sucessão do trono egípcio, em 47 a.C., em que César tomou o partido de Cleópatra contra o irmão desta, Ptolomeu XIII. Hoje tende-se a oferecer alguma resistência a essa opinião e atribui-se mais a destruição da Biblioteca à guerra entre Aureliano e Zenóbia, em 272, em que o bairro do Museu terá sido arrasado (Amm. Marc. 22.16.15). A questão continua, porém, a suscitar o debate, também porque as fontes se contradizem entre $\mathrm{si}^{2}$. Se ela nos merece tanta atenção é porque, para todos os efeitos, o Serapeum assume as funções do Museu após a destruição deste.

Originalmente, porém, o templo terá funcionado simplesmente como centro de apoio à Biblioteca de Alexandria, razão porque a sua colecção

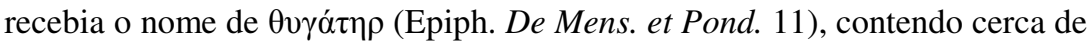
42.800 rolos no tempo de Calímaco, muitos cópias de originais da bibliotecamãe (Brill's New Pauly, s.v. Library, II.B.2) ${ }^{3}$. A única fonte para este número

2 Sobre a vexata quaestio da destruição ou não da Biblioteca no fogo de 47 a.C., aconselha-se a leitura de Parsons (1952: 288-319), que passa em revista, coligindo, as fontes, desde César a Orósio, coleccionando ainda as opiniões de outros estudiosos modernos. Numa obra nem sempre pautada pelo rigor científico, este é, porém, um apêndice que muito temos de agradecer.

3 De acordo com Gibbon (capítulo 28, nota 41), e, na sua esteira, de outros, a biblioteca do Serapeum conteria ainda mais 200.000 volumes, a totalidade da biblioteca de Pérgamo, oferta de António a Cleópatra (Plu. Ant. 58). A sua opinião, porém, assenta no pressuposto, discutível, como vimos, de que a biblioteca original foi destruída por César (a partir do fundo de Pérgamo ter-se-ia então criado a colecção do Serapeum). Gibbon parece também não tomar em consideração o facto de que, na narrativa de Plutarco (a única fonte que o refere), esta informação é explicitamente 
é o fragmento CGF p.19 do gramático bizantino Tzetzes (c.1110-1180), que, escrevendo mais de um milénio depois dos acontecimentos a que se refere, a ser aceite como autoridade, deve sê-lo com precaução. Será importante notar que Tzetzes não se refere explicitamente ao Serapeum, falando apenas numa «biblioteca externa». Também não é seguro que o Serapeum acumulasse desde a sua fundação as funções de templo e biblioteca, como o fragmento CGF p.19 parece implicar. Orósio (Hist. 6.15.32) favorece a opinião, pelo contrário, de que só depois da destruição da Biblioteca em 47 a.C. (tese que subscreve) surgiram, na tentativa de a emularem, colecções noutros templos (não especificados), que poderíamos talvez identificar tentativamente com o Augusteu (Philo Leg. 151) e o Serapeum. Epifânio (De Mens. et Pond. 11) é demasiado confuso e vago sobre esta questão para que dele possamos concluir o que quer que seja com certeza e os dados arqueológicos não nos podem ajudar (McKenzie et al., 2004: 100), não permitindo excluir a hipótese de a biblioteca datar dos Ptolomeus, mas também não oferecendo quaisquer provas concretas que confirmem o testemunho de Tzetzes.

A primeira menção certa à $\theta v \gamma \alpha ́$ tๆ $\rho$ data apenas do final do século II d.C. e devemo-la, ironicamente, a um cristão, Tertuliano (Apol. 18), que afirmava ser possível consultar no templo a Septuaginta, que, pelo testemunho de São João Crisóstomo ( $A d v$. Jud. 1.6), sabemos que continuava disponível nos anos imediatamente anteriores à destruição do Serapeum, provando a utilização do templo como biblioteca. Guardavam-se aí também as traduções da Bíblia Hebraica por Áquila de Sinope, Símaco Ebionita e Teodócio (Epiph. De Mens. et Pond. 11), todos autores judeus do século II, de cujas obras Orígenes se valerá para a edição da Hexapla, o seu estudo comparado das traduções do Antigo Testamento. Não é arriscado considerar que as terá consultado in loco. Podemos, pois, fazer fé no testemunho de Tertuliano e aceitar que, pelo menos desde o final do século II, ou seja, desde a reconstrução romana do santuário ${ }^{4}$, depois do incêndio de 181 , o Serapeum

usada por inimigos de Marco António para o denegrir, pelo que temos dúvidas da sensatez em a aceitar.

${ }^{4} \mathrm{O}$ pouco espaço de que dispomos e o facto de não ser esse o tema do nosso artigo não nos permitiram expor aqui a história do Serapeum. O santuário sofreu, porém, uma profunda remodelação e ampliação entre 181 e 217 , respectivamente, com base nas fontes e nos dados arqueológicos, o terminus post quem e ante quem para a reconstrução que se seguiu ao fogo que lavrou no recinto no final do segundo século (McKenzie et al., 2004: 86, 98-99). O facto de a primeira referência a uma 
funcionava como biblioteca. Os livros, muito provavelmente, estariam alojados nas várias salas ao longo da colunata oeste (McKenzie et al., 2004: 99).

O templo de Serápis, do qual Amiano Marcelino disse que nada havia no mundo, fora o Capitólio, mais digno de admiração (22.16.12), acabou por ser destruído pela população cristã em 391, sob a supervisão de Teófilo, patriarca de Alexandria, e com a autorização do imperador. Rufino (c.340410), a nossa fonte mais antiga, conhecia bem o edifício, porque havia estudado no Didascaleion, a escola catequética de Alexandria. Na sua própria história da Igreja, uma continuação do trabalho de Eusébio de Cesareia (como Xenofonte com Tucídides), Rufino descreve em pormenor os eventos que conduziram à destruição do Serapeum (HE 2.22-23). Teófilo, com a sanção de Teodósio, teria iniciado a recuperação de um velho templo pagão, entretanto abandonado. Durante as obras para converter o espaço numa igreja, ter-se-ão descoberto os recessos subterrâneos onde se celebravam os mysteria, que Rufino classifica como antros mais propícios a crimes que a cerimónias sagradas. Os pagãos, diz-nos, temendo a revelação dos seus rituais celerados, avançaram contra os cristãos, que retaliaram, forçando-os a retirarem-se para o Serapeum. Alguns cristãos foram feitos reféns e obrigados a adorar o deus; se recusavam, eram torturados e mortos. À cabeça dos pagãos, estava Olímpio, personagem que Amenábar recupera. O prefeito da cidade, incapaz de resolver a situação, comunicou o caso a Teodósio. Este perdoou aos pagãos, mas ordenou também a destruição dos ídolos, bellorum causa. O Serapeum, de acordo com o testemunho de Rufino, acabou por ser totalmente arrasado ( $H E$ 2.27), bem como os restantes templos da cidade ( $H E$ 2.28), e no lugar da antiga casa de Serápis foi erguida uma igreja e um martyrium que acolhia as relíquias de São João Baptista.

Em traços gerais, Sozomeno (c.400-450) e Teodoreto (c.393-457) corroboram a versão de Rufino, que terá sido, de resto, uma das suas fontes. Sozomeno diz-nos que o templo que Teófilo pretendia transformar numa igreja era dedicado a Diónisos e que foi a exposição pública dos falos rituais encontrados nos adyta, objectos que os cristãos não deixaram de ridicularizar,

biblioteca no Serapeum coincidir precisamente com a intervenção romana no espaço reforça a nossa convicção, que não erigimos, porém, em conclusão científica, de que só a partir deste período - desta remodelação - é que o Serapeum acolheu livros, de facto. 
que irritou os pagãos (7.15). O Serapeum, depois de tomado pelos cristãos, teria sido então convertido numa igreja, como se vê no filme, recebendo o nome do imperador Arcádio (ibid). Sozomeno é, contudo, suficientemente ambíguo para o podermos reconciliar com o que lemos em Rufino. $\mathrm{O}$ autor, de facto, refere que a transformação do Serapeum em igreja aconteceu apenas algum tempo depois (Arcádio, de resto, sobe ao trono apenas em 395, terminus post quem). Este espaço temporal pode bem corresponder aos anos de construção da nova igreja e o termo $\mu \varepsilon т \varepsilon \sigma \kappa \varepsilon \cup \alpha ́ \alpha \theta \eta$ deve, se calhar, ser entendido de uma forma mais lata. Uma leitura literal isola Sozomeno, pois é o único que dá conta do aproveitamento cristão do Serapeum. Teodoreto, por sua vez, limita-se a narrar a destruição à machadada da grande estátua de Serápis, cuja cabeça foi arrastada pela rua como no Iraque a de Saddam (HE 5.22). Não faz, contudo, qualquer referência específica à demolição do Serapeum, limitando-se a saudar a acção de Teófilo, que, diz, por toda a cidade procedeu à razia dos templos $($ ibid $)$.

Sócrates Escolástico (c.380-?) conta, porém, uma história diferente (5.16-17), que ouviu de dois dos seus professores, antigos sacerdotes pagãos fugidos de Alexandria depois dos eventos de 391. Teófilo teria obtido do imperador ordens para destruir todos os templos da cidade (cf. C. Th. 16.10.11). Depois de ter profanado um mithraeum expondo os objectos de culto ao escárnio público, o patriarca teria avançado sobre o Serapeum, destruindo-o. Os pagãos, especialmente os professores de filosofia, acabaram por reagir quando Teófilo ordenou que se mostrassem no fórum os falos de Príapo. Avançaram então sobre os cristãos matando o maior número possível. Estes reagiram, e foi grande a mortandade de ambos os lados. Muitos pagãos acabaram depois por fugir e, findo o tumulto, Teófilo, com as tropas imperiais, procedeu à demolição dos restantes templos da cidade. Note-se a forma natural como a destruição do Serapeum parece ocorrer, sem resistência da parte dos pagãos (ausente também em Teodoreto).

Não nos parece possível unificar a narrativa de Sócrates e a de Rufino, as duas credíveis e, tudo leva a crer, em primeira mão. De facto, se a versão de Rufino é usada pelos historiadores cristãos posteriores, o que poderia abonar a seu favor, Eunápio, filósofo e historiador pagão do século IV, parece confirmar a narrativa de Sócrates. Em Vitae 472, lemos que os cristãos não

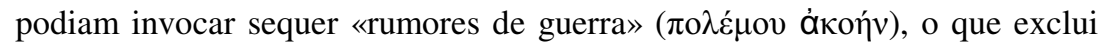
ataques prévios dos pagãos, e que «triunfaram, sem resistência, sem luta» (Eunápio refere-se à tomada do Serapeum). Parece-nos possível, porém, elencar três eventos-chave, mesmo não sendo completamente certa a sua 
ordem: (1) cristãos provocam pagãos ridicularizando publicamente objectos de culto encontrados num templo de que se apoderam com autorização de Teodósio (o filme simplifica isto, pondo simplesmente os cristãos a troçarem das estátuas dos deuses na ágora); (2) confrontos cristãos-pagãos nas ruas; (3) tomada do Serapeum pelos cristãos e destruição da grande estátua de Serápis.

Se (3) implicou a destruição completa do templo é o que procuraremos perceber agora, questão importante para sabermos se a hipótese de Sozomeno (e do filme) da conversão do Serapeum em igreja tem cabimento. Rufino, como já acima se disse, afirma que o Serapeum foi arrasado («nam in Serapis sepulcro, profanis aedibus complanatis») (HE 2.27). Contudo, em $H E$ 2.28, lê-se o seguinte: «derrubados os vestígios da idolatria, nos templos outrora profanos elevam-se tectos de ouro». Podíamos ler aqui uma referência velada à conversão dos templos em igrejas, não fora talvez a frase que se lhe segue: «Pouco terei dito, se disser que todos os templozinhos (aediculae) abandonados que havia em Alexandria, dedicados fosse a que demónio fosse, caíram (ceciderunt) quase coluna por coluna». Rufino explica então como por todo o Egipto os templos «ad solum deducta sunt». Como interpretar os «tectos de ouro» de 2.28 é uma discussão que não queremos trazer para aqui. Pensamos ter já mostrado não servir para defender a tese de que o Serapeum não foi arrasado, mas convertido numa igreja.

Eunápio também não poupa o templo, no seu relato gráfico da destruição: «e tudo sucedeu como nos mitos dos poetas, quando os gigantes

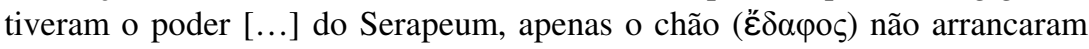
pelo peso das pedras, pois não eram facilmente re-movíveis» (Vitae, 472). O filósofo é extremamente claro: «o culto quer nos templos por Alexandria quer no santuário de Serápis dissipou-se ( $\delta \varepsilon \sigma \kappa \varepsilon \delta \alpha ́ v v v \tau o)$; não o culto apenas, mas

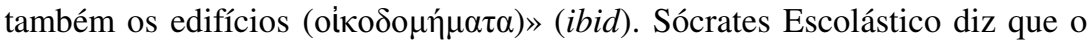

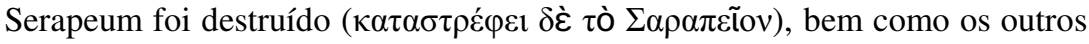

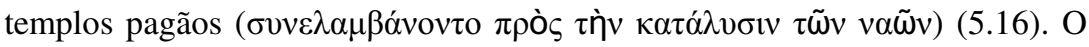
facto de Teófilo contar com o apoio de tropas imperiais parece apontar para algo mais do que um mero exercício de iconoclastia. Teodoreto, não se pronunciando sobre o Serapeum em particular, louva, como dissemos, a

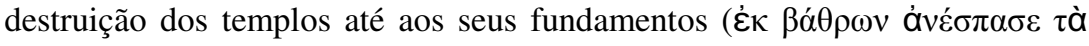

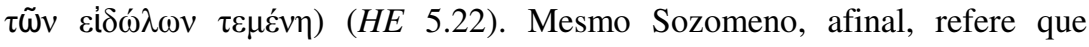
Teodósio, informado dos acontecimentos no Serapeum, «mandou destruir

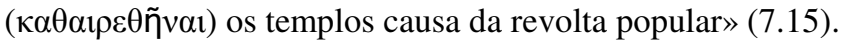

A verdade é que a destruição de templos se havia tornado uma prática comum, que o édito de Teodósio em 391 (C. Th. 16.10.10) veio, de alguma 
forma, legitimar. Eusébio descreve já a demolição do santuário de Asclépio por Constantino (V. Const. 3.56) e é impossível não recordar o pungente discurso do filósofo pagão Libânio, Pro Templis, em que este solicita a intervenção do imperador face à destruição gratuita de templos que se começava a registar (ainda antes de 391). Libânio fala em «telhados destruídos, paredes arrasadas, estátuas derrubadas, altares desfeitos» (8), perguntando qual, afinal, a vantagem em destruir ( $\delta 1 \alpha \varphi \theta \varepsilon i ́ p \varepsilon \imath v)$ o que pode ser usado para outros fins e é, aliás, propriedade imperial (43). Libânio condena em seguida de forma explícita a participação do exército na demolição dos santuários (ibid). Pensaria talvez em Cinégio, prefeito do pretório do Oriente (384-388) e hieroclasta-mor. A sua prece, «oxalá [o Serapeum] nunca sofra isto» (44), tanto quanto as fontes nos permitem ajuizar, não foi atendida pelos deuses e o grande templo de Alexandria foi mesmo arrasado em 391.

Os arqueólogos não encontraram quaisquer vestígios de igrejas no $\tau \varepsilon \dot{\mu} \mu \varepsilon v o \varsigma$, mas 25 metros a oeste do recinto sagrado descobriram o que pode bem ser as fundações de uma igreja, datadas precisamente do final do século IV ou século V (McKenzie et al., 2004: 108). No mesmo sítio, descobriramse cisternas com cruzes e baptistérios (ibid). Se a igreja e o martyrium foram construídos fora do complexo do Serapeum isso explica também a referência de Evágrio Escolástico ( $H E$ 2.5) ao velho templo de Serápis, onde, segundo o historiador cristão do século sexto, as tropas imperiais, em 451, aquando de mais uma revolta popular em Alexandria a propósito da eleição de um patriarca, se refugiaram (sem sucesso, que o povo os queimou vivos lançando fogo ao templo). Este passo, claro, parece apontar para a sobrevivência do templo pós-391, mesmo se nunca como igreja. Como conciliar esta permanência do Serapeum com o testemunho das fontes que vimos anteriormente é tarefa ingrata, se não mesmo impossível.

Nenhum dos autores acima referidos, nos seus relatos da tomada do

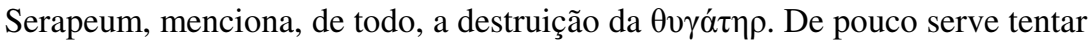
escamotear o facto afirmando que se trata de fontes cristãs, naturalmente pouco interessadas em dar conta do episódio, porque (1) Eunápio é pagão, recordemo-lo, e (2) Sócrates é uma das nossas fontes para a morte de Hipácia, que não deixa de relatar, embora horrorizado com o comportamento dos seus irmãos cristãos e tomando até quase o partido da filósofa. $\mathrm{Na}$ realidade, apenas Orósio (Hist. 6.15.32), que escreve na segunda década do século $\mathrm{V}$, pode ser usado para sustentar a tese de que a colecção do templo foi destruída: «e hoje restam, também nós as vimos, estantes nos templos; 
pilhados estes, estas foram esvaziadas pelos nossos e no nosso tempo, recordam - e isto é certo ser verdade». Como acima dissemos, não se sabe, porém, se Orósio se está aqui a referir ao Serapeum.

Certos autores, perante o silêncio das fontes, afirmam então ou que nunca houve livros no Serapeum, o que nos parece uma hipótese radical, mas, sobretudo, oposta a quantos testemunhos temos, ou que a biblioteca não foi destruída em 391, mas em 642, aquando da conquista árabe da cidade. Esta última possibilidade, mesmo se maioritariamente abandonada pela historiografia moderna, tem vários advogados que, como prova da sobrevivência da biblioteca, apontam o testemunho de Aftónio, amigo de Libânio e professor de retórica, e se baseiam num conjunto de fontes árabes

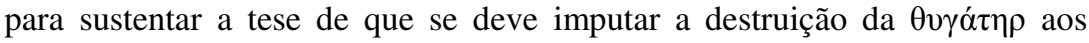
muçulmanos.

Nos Progymnasmata 12, o trecho de Aftónio em causa, este fala de uma colecção de livros na acrópole de Alexandria (onde se situava o Serapeum) e refere a existência, no mesmo espaço, de compartimentos para a adoração dos deuses, o que nos permite estabelecer muito claramente como terminus ante quem do texto 391. Parsons, que discorda, escreve (1952: 367): «the other rooms that had been used for the pagan service, we may be sure were now empty or were warehouses for the refuse of the destroyed temple contents, or used for other purposes». Não podemos deixar de sentir que o autor violenta o texto original: para quem está «sure», apresenta muitos «or».

Resta-nos avaliar as fontes árabes. O nosso desconhecimento da língua obrigou-nos a confiar nas traduções fornecidas por Parsons. A primeira referência à destruição da biblioteca pelas tropas de Amr ibn al-Ās é de Abdal-latif al-Baghdadi (1162-1231), que no seu livro sobre o Egipto comenta, en passant, que a biblioteca criada por Alexandre na academia por ele erigida fora mandada queimar por Omar, o califa. Há aqui, claro, uma confusão entre a Biblioteca de Alexandria e a do Serapeum, que, porém, observamos já noutros escritores dos primeiros séculos, e.g. Tertuliano. Mais importante será talvez realçar que Abd-al-Latif dista mais de cinco séculos dos eventos. A narrativa detalhada da destruição devemo-la, contudo, a um seu contemporâneo, Ibn al Kifti (1172-1248), onde encontramos a famosa justificação de Omar para queimar os livros: se estão de acordo com o Corão, são desnecessários; se o contradizem, por maioria de razão devem ser eliminados. Os rolos teriam sido utilizados como combustível para aquecer os banhos da cidade durante seis meses. 
Apesar do testemunho de Abd-al-latif e Ibn al Kifti (e de outros, na sua esteira), não podemos deixar de sublinhar que os autores mais próximos da conquista árabe de Alexandria em 642 nada dizem sobre a destruição da biblioteca. João de Nikiû, que viveu na passagem do século VII para o VIII, São Teófanes (c.758-817), São Nicéforo (c.758-828), Ibn Abd-el-Hakam (m. c.870), autor da História da Conquista do Egipto, do Norte de África e de Espanha, Muhammad ibn Jarir al-Tabari (838-923), Abu al-Hasan Ali alMasudi (c.896.956) e Said ibn Batriq, também conhecido pelo nome cristão de Eutíquio (877-940) — todos escrevem sobre a tomada de Alexandria; nenhum fala da destruição dos livros. Parsons (idem: 422-424), louvando muitos deles (al-Tabari, por exemplo, é conhecido como o Heródoto árabe), menoriza, contudo, o seu testemunho, nisto pondo a nu os seus critérios duplos, pois se o silêncio das fontes sobre a destruição da colecção do Serapeum conta para ele como prova maior de que a biblioteca permaneceu intacta, o silêncio de todas estas outras fontes em relação à destruição dos livros pelos árabes é, pelo contrário, ignorado, na prática.

Mesmo supondo que a $\theta$ vó́ convencidos de que o seu fim se tenha ficado a dever aos árabes. A rejeição desta tese obriga quem o faz, porém, a avançar com uma teoria alternativa para o desaparecimento da biblioteca, da qual não há mais registo nas fontes. Uma biblioteca deste tamanho não desaparece sem nota, como que roubada por Carmen Sandiego, a não ser que desposemos, adaptada, a verdade de Eliot: «This is the way the library ends/Not with a bang but a whimper». Contudo, não conseguimos também subscrever alegremente a tese da destruição pelos cristãos da colecção do Serapeum, quando, como vimos, nenhuma fonte lhe faz alusão e os rolos se encontravam guardados em salas à parte, mesmo se possivelmente intercaladas com outras para adoração dos deuses (Aftónio não é claro nisso), as quais não teriam escapado ao zelo iconoclasta dos cristãos.

Há que ter humildade para admitir o que não se sabe. Da mesma maneira que não temos certezas sobre quando a Biblioteca de Alexandria foi destruída, também não podemos afirmar com segurança quando a colecção do Serapeum deixou de existir. Que tal tenha sucedido em 391, com a demolição do templo pelos cristãos, é talvez a hipótese mais forte, mas não podemos comprometermo-nos com ela totalmente. O filme, porém, não podia ficar suspenso nesta aporia e teve de optar por uma narrativa; não criticamos a sua escolha. Apenas lamentamos, como já indicámos, a identificação entre a biblioteca maior e a menor, fazendo ao espectador crer tratar-se de uma e da 
mesma, e, por outro lado, a não destruição do Serapeum (mau grado os testemunhos a favor) e a sua conversão em igreja.

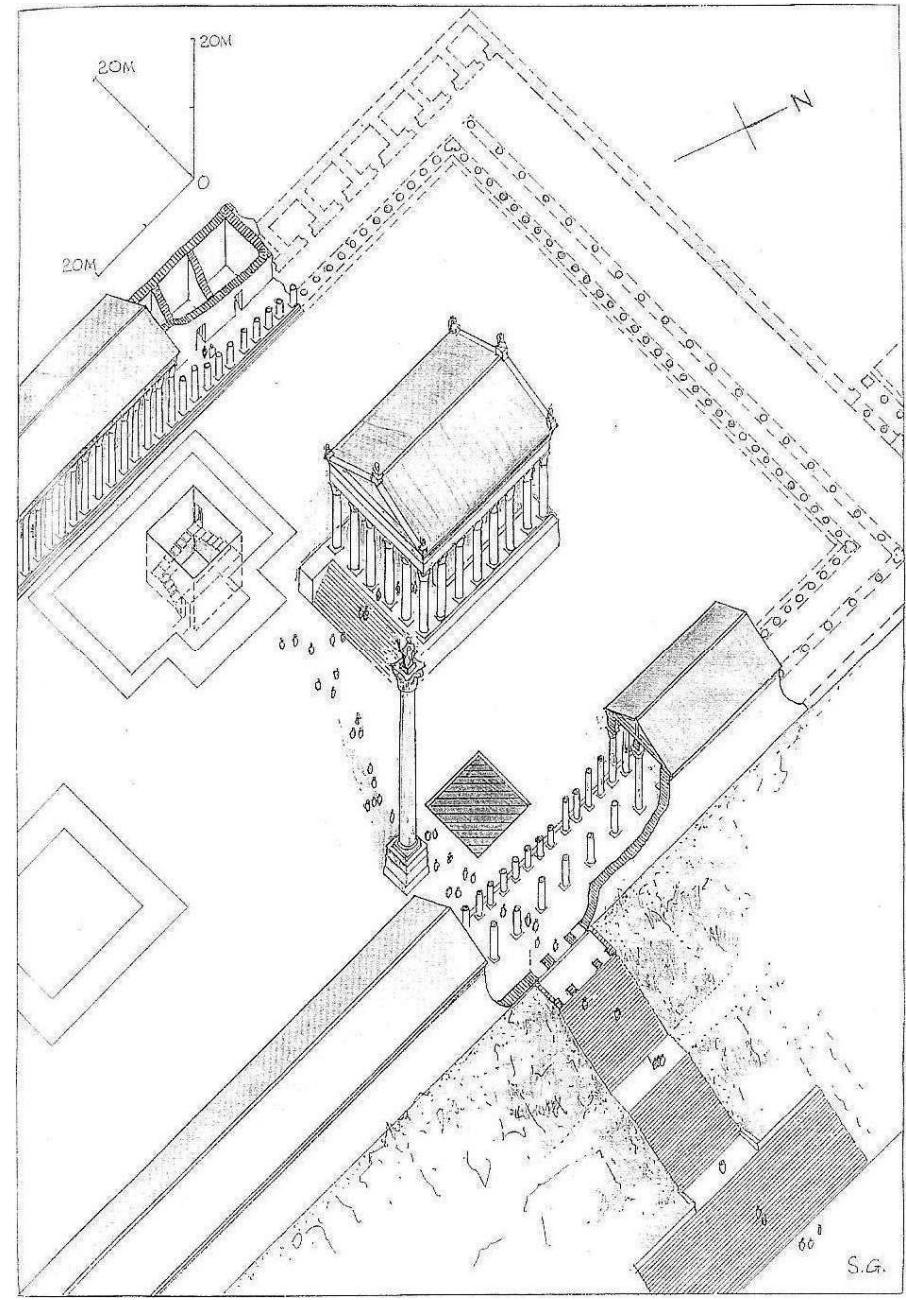

Figura 1 O Serapeum de Alexandria. Pormenor de uma reconstrução axonométrica do recinto no período romano, depois da instalação da Coluna de Diocleciano (298 d.C.). Ilustração por Sheila Gibson in McKenzie et al., 2004: Plate I. 
EDIÇÕES DAS OBRAS TRADUZIDAS:

BIVARIUS, Franciscus, HAVERCAMPUS, Sigebertus (1846), F.L. Dextri necnon Pauli Orosii Opera Omnia. Paris: J.-P. Migne. (edição e notas).

NORMAN, A. F. (1977), Libanius. Selected Works. Vol. II: Selected Orations. Cambridge, MA: Harvard University Press. (introdução, tradução e notas).

SCHULZE, Joan. Ludov. (1864), Theodoreti Cyrensis Episcopi Opera Omnia - III. J.-P. Migne. (edição, tradução e notas).

VALlARSI, Dominic (1878), Tyrannii Rufini. Opera Omnia. Paris: J.-P. Migne. (edição, tradução e notas).

VAlOIS, Henri (1864), Socratis Scholastici, Hermiae Sozomeni Historia Ecclesiastica. Paris: J.-P. Migne. (edição, tradução e notas).

WRIGHT, Wilmer C. (1968), Philostratus. Lives of Sophists. Eunapius. Lives of Philosophers. Cambridge, MA: Harvard University Press. (introdução e tradução).

BIBLIOGRAFIA CITADA:

CANCIK, Hubert \& SCHNEIDER, Helmuth (eds.) (2002), Brill's New Pauly. Encyclopedia of the Ancient World. Leiden \& Boston: Brill.

GIBBON, Edward (1862), The History of the Decline and Fall of the Roman Empire. Volume III. London: John Murray.

MCKENZIE, Judith, GIBSON, Sheila, REYES, A. T. (2004), 'Reconstructing the Serapeum in Alexandria from the Archeological Evidence', Journal of Roman Studies 94: 73-121.

PARSONS, Edward Alexander (1952), The Alexandrian Library, Glory of the Hellenic World. Its Rise, Antiquities, and Destructions. London: Cleaver-Hume Press. 